\title{
La seguridad alimentaria en su huerto familiar
}

PAMELA M. GEISEL, Coordinadora Académica, Programa Estatal Jardineros Maestros de la Universidad de California; y DONNA C. SEAVER, Representante del Programa, Programa Estatal Jardineros Maestros de la Universidad de California. Originalmente publicado como Food Safety in Your Home Vegetable Garden (ANR Publication 8366).

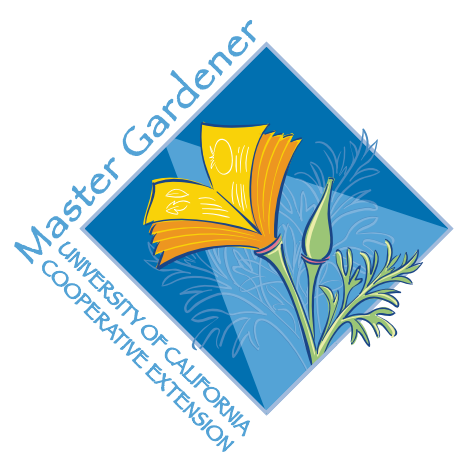

"Episodios de enfermedades causadas por alimentos ocupan los titulares informativos continuamente. En los Estados Unidos se estima que unos 76 millones de personas se enferman a causa de comida contaminada cada año. Como resultado, más de 325,000 son hospitalizadas y alrededor de 5,000 personas mueren". Todos corremos el riesgo de enfermarnos con comida contaminada, pero los niños menores de 5 años, adultos mayores de 50, personas con diabetes, quienes toman antibióticos o antiácidos, y quienes tienen su sistema inmunológico comprometido están en mayor riesgo.

Posiblemente ha escuchado de brotes de enfermedades causadas por bacterias como Salmonella en tomates y melones y E. coli O157:H7 en lechuga y espinaca. Estas bacterias que causan enfermedades se encuentran en excremento de animales y de humanos.

Del huerto a la cocina, hay muchas oportunidades para que bacterias, virus y parásitos contaminen verduras y frutas. El agua, herramientas, animales y el suelo contaminado con estiércol podrían ser fuentes de contaminación en su huerto.

\section{Reduzca el riesgo de contaminar los alimentos que cultiva en su huerto}

\section{Suelo limpio}

Para mayor seguridad, cuando cultive verduras con hojas comestibles y otros productos del huerto que se comen crudos, considere no usar estiércol ni correctores de suelos compostados o estabilizados que contengan cualquier componente de origen animal, aunque el riesgo de patógenos trasmitidos por los alimentos en abonos procesados correctamente es bajo. Si los utiliza, incorpore estos materiales al suelo, y no los deje en la superficie.

Si aplica en el huerto correctores de suelo hechos con estiércol, considere obtener materiales compostados o estabilizados comercialmente. El estiércol que no ha sido compostado comercialmente puede no estar completamente procesado. Sin embargo, recuerde que ningún material compostado se garantiza de estar 100 por ciento libre de bacteria como E. coli. 


\section{Agua limpia}

Esté al tanto de la calidad de su agua de riego. Agua municipal de la llave o de un pozo construido correctamente que se examine regularmente son las fuentes de agua preferidas. Utilice agua de la llave para regar por aspersión o para rociar las partes comestibles de plantas y cuando lave los productos del huerto.

\section{Manos limpias}

Utilice guantes protectores o desechables cuando trabaje con estiércoles y abono (compost). Siempre lávese bien las manos después de trabajar con estos materiales.

\section{Superficies limpias}

Antes y durante la cosecha, utilice herramientas, guantes, contenedores y superficies de trabajo limpios. Ponga atención a lo que las manos y herramientas han tocado antes de seguir con otras labores que involucren plantas comestibles, tales como cosecharlas. Lave las herramientas, zapatos o botas en un sitio alejado del huerto. Blanqueador diluido ( 1 cucharadita en 4 tazas de agua) o vinagre blanco puro son seguros para desinfectar las superficies de trabajo. (Para equivalencias entre el sistema de medidas métrico y el de EEUU, se adjunta una tabla de conversiones al final de esta publicación.)

\section{Considere la seguridad alimentaria en cada fase de su huerto familiar}

Siga estas recomendaciones para reducir el riesgo de exponer lo que cultiva en su huerto a contaminantes en el agua, suelo y fertilizantes, manos y superficies.

\section{Antes de sembrar}

- Identifique fuentes de agua para riego: de bajo riesgo - agua potable municipal de riesgo mínimo - agua potable del pozo si se le da buen mantenimiento a la envoltura o forro del pozo y éste está enlechado o acabado con argamasa, y el ganado se mantiene fuera del área de recarga activa y la zona de infiltración del pozo séptico

de alto riesgo - agua superficial y represa

- Aprenda acerca de la calidad de su agua de riego y hágale pruebas a las fuentes de donde proviene el agua superficial o de pozos para detectar la presencia de E. coli y otras bacterias coliformes (indicadores fecales generales); de estar presentes, estas indican que el agua ha podido haber sido contaminado por fuentes fecales que pueden contener patógenos dañinos. A continuación brindamos recomendaciones para examinar las fuentes de agua. Para información adicional o recomendaciones locales, consulte a un asesor de Extensión Cooperativa o comuníquese con el Departamento de Servicios de Salud de California (DHS, por sus siglas en inglés) (http://www.dhs. ca.gov/) o la Junta de Agua del Estado (http:// www.swrcb.ca.gov/).

- Agua municipal: Se recomienda el uso de dispositivos para prevenir el reflujo del agua.

- Agua de pozo: Haga pruebas dos veces al año y trate el pozo si las pruebas indican la presencia de bacterias fecal coliformes. Póngase en contacto con el departamento de salud pública de su condado para obtener las pautas para el tratamiento de pozos y procedimientos para hacer nuevas pruebas.

- Agua superficial: Un análisis de laboratorio del agua superficial le dará la información necesaria para tomar medidas correctivas para contar con un suministro de agua sana y segura. Aunque no muy común para el huerto familiar, una prueba de agua durante la época de cultivo le ayudará a saber la calidad de una fuente de agua de superficie disponible y patrones que servirán para alertarlo respecto a actividades que causan contaminación. Póngase en contacto con la oficina local de DHS o Extensión Cooperativa para obtener información sobre servicios de laboratorios en su zona.

- Hay disponibles juegos para hacer pruebas de agua en el hogar que incluyen pruebas rápidas para detectar indicadores fecales y que brindan orientación general, pero éstos aun no han sido evaluados por investigadores de la Universidad de California.

- Para mayor seguridad cuando cultiva verduras con hojas comestibles y otras verduras que se consumen crudas, considere no usar estiércol compostado o estabilizado ni correctores que contengan componentes de origen animal.

- Evite usar estiércoles no compostados.

- Evite sembrar verduras con hojas comestibles y otras verduras y frutas cerca de sitios para animales (corrales, lotes, potreros) donde el polvo llevado por el viento y el escurrimiento de agua superficial pueden causar contaminación de los productos del huerto. 


\section{Producción}

- Esté muy pendiente de la posibilidad de que las herramientas del huerto, manos, ropa y zapatos se contaminen al trabajar con estiércoles y materiales de abono. Esté muy consciente de que las manos o guantes sucios pueden transferir patógenos de estiércol o materiales orgánicos aun no totalmente compostados a cultivos o contenedores.

- Use guantes protectores o desechables cuando trabaja con estiércol y compost, especialmente si tiene heridas abiertas en las manos. Siempre lávese las manos muy bien después de trabajar con estos materiales y, por lo menos, lave las herramientas, zapatos o botas con una manguera en un lugar lejos del huerto.

- Antes y después de tocar frutas y verduras frescas, lávese las manos, limpiándose cuidadosamente alrededor de las uñas.

- No agregue estiércol fresco a una pila de compost existente.

- Lo ideal sería que, durante la época de cultivo y cosecha, pudiera mantener animales salvajes y domésticos alejados de los montones de abono y sitios con plantas comestibles.

- Para reducir el riesgo de contaminación, utilice agua de la llave para regar por aspersión o para rociar las partes comestible de las plantas

- Considere el uso de riego por goteo para reducir mojar las superficies de hojas y frutas.

\section{Cosecha}

- Lávese las manos antes de tocar las verduras y frutas.

- Utilice herramientas, contenedores, guantes, etc., limpios.

- Mientras esté en el huerto, quite el exceso de tierra de las verduras y frutas.
- Manipule las verduras y frutas con cuidado para no estropearlas.

\section{Manejo de poscosecha}

- Lávese las manos antes de tocar las verduras y frutas.

- Utilice agua de la llave para lavar todas las verduras $\mathrm{y}$ frutas.

- Lave las frutas y verduras con un cepillo limpio bajo agua de la llave para quitarles la tierra y posibles contaminantes en vez de echarlas todas en un tazón para lavarlas.

- El blanqueador diluido (1 cucharadita de blanqueador en 4 tazas de agua) o vinagre blanco puro son seguros para desinfectar superficies de trabajo.

- Siempre cubra y refrigere frutas y verduras cortadas cuando las prepara de antemano.

- Tire frutas y verduras cortadas si han estado más de 2 horas a temperatura ambiente o más de 1 hora a temperaturas de más de $90^{\circ} \mathrm{F}\left(32^{\circ} \mathrm{C}\right)$.

Para más información, contacte a los Jardineros Maestros locales o busque en línea: http:// camastergardeners.ucdavis.edu.

Agradecemos el apoyo para este proyecto de Elvenia J. Slosson Research Endowment for Ornamental Horticulture. Contenido usado en esta publicación fue tomado, con permiso, de Food Safety Begins on the Farm: Reduce Microbial Contamination with Good Agricultural Practices, por Elizabeth A. Bihn, Robert B. Gravani, Janet E. Hawkes, Marvin P. Pritts, Anusuya Rangarajan y Donna L. Scott. Nuestras gracias a Trevor Suslow por la revisión y sugerencias técnicas. Traducción al español: Andrew Kramer y Myriam Grajales-Hall. Ilustraciones y diseño del póster: Will Suckow Ilustración.

\section{RECURSOS EN LÍNEA}

\section{Sitios web}

\section{En español}

Las prácticas agrícola buenas de la Universidad de California

http://groups.ucanr.org/UC_GAPs/Las_Publicaciones_en_Español/

\section{En inglés}

\section{California Master Gardeners}

http://camastergardeners.ucdavis.edu/

\section{Center for Disease Control}

http://www.cdc.gov 
Food Safety Fact Sheets and link to EPA Consumer Handbook for Composting http://vric.ucdavis.edu

FoodSafe Program http://foodsafe.ucdavis.edu

Gateway to Government Food Safety Information http://www.foodsafety.gov/

Good Agricultural Practices Network for Education \& Training http://www.gaps.cornell.edu/

Guide to Minimize Microbial Food Safety Hazards for Fresh Fruits and Vegetables- Guidance for Industry (FDA) http://www.foodsafety.gov/ dms/prodguid.html

University of California Good Agricultural Practices http://ucgaps.ucdavis.edu/

\section{Publicaciones /Folletos}

\section{En español}

Extensión en español (colección de publicaciones) http://extensionenespanol.net/publications.cfm

\section{En inglés}

Good Agricultural Practices - A Self-Audit for Growers and Handlers http://ucce.ucdavis.edu/files/filelibrary/5453/4362.pdf

Harvesting and Storing Your Home Orchard's Nut Crop: Almonds, Walnuts, Pecans ANR Publication 8005

http://anrcatalog.ucdavis.edu/InOrder/Shop/ItemDetails.asp?ItemNo=8005

Hand Sanitation (ppt to pdf) http://ucgaps.ucdavis.edu/documents/Slide_presentations2518.pdf

Key Points of Control and Management for Microbial Food Safety: Edible Landscape Plants and Home Garden Produce

ANR Publication 8101

http://anrcatalog.ucdavis.edu/InOrder/Shop/ItemDetails.asp?ItemNo=8101

Key Points of Control and Management of Microbial Food Safety Concerns for Edible Landscape and Home Gardening (brochure) http://ucce.ucdavis.edu/files/filelibrary/5453/4364.pdf

Microbial Food Safety $\underline{\text { SS }}$ your Responsibility! http://vric.ucdavis.edu/veginfo/foodsafety/foodsafety.htm

National GAPs Educatonal Materials http://www.gaps.cornell.edu/educationalmaterials.html

Producing Quality Almonds: Food Safety Starts on the Farm ANR Publication 8126 http://anrcatalog.ucdavis.edu/InOrder/Shop/ItemDetails.asp?ItemNo=8126

Safe Handling of Fruits and Vegetables ANR Publication 8121 http://anrcatalog.ucdavis.edu/InOrder/Shop/ItemDetails.asp?ItemNo=8121

UC Postharvest Technology Research and Information Center (Food Safety Publications) http://postharvest.ucdavis.edu/postharvestdata/datareport.cfm?reportnumber=204\&catcol=1809\&categ orysearch=Food $\% 20$ Safety 


\section{REFERENCIAS}

1. Rangarajan, A., M. Pritts, S. Reiners y L. Pedersen. 2000. Food safety begins on the farm: Reduce microbial contamination with good agricultural practices. Ithaca, NY: Cornell University. Good Agricultural Practices (GAP) Program Web site, http://www.gaps.cornell.edu/Educationalmaterials/ Samples/PamphletEng.pdf

\section{CONVERSIONES INGLÉS-MÉTRICO}

\begin{tabular}{|l|c|c|c|}
\hline Inglés & $\begin{array}{c}\text { Factor para convertir de } \\
\text { inglés a métrico }\end{array}$ & $\begin{array}{c}\text { Factor para convertir de } \\
\text { métrico a inglés }\end{array}$ & Métrico \\
\hline cucharadita & 4.93 & 0.20 & mililitro (ml) \\
\hline taza & 236.6 & 0.004 & mililitro (ml)
\end{tabular}

\section{INFORMACIÓN DE PEDIDOS}

Si desea obtener esta publicación, visite el sitio web de ANR Communication Services (http://anrcatalog.ucdavis.edu) o póngase en contacto con:

\section{University of California}

Agriculture and Natural Resources

Communication Services

6701 San Pablo Avenue, 2nd Floor

Oakland, California 94608-1239

Telephone 1-800-994-8849 or 510-642-2431

FAX 510-643-5470

E-mail: danrcs@ucdavis.edu

CEn 2009 por los Regentes de la Universidad de California,

División de Agricultura y Recursos Naturales. Todos los derechos reservados.

Ninguna parte de esta publicación puede ser reproducida, almacenada en un sistema recuperable, o transmitida, de cualquier forma o por cualquier medio, electrónico, mecánico, de fotocopiado, grabación, u de otra manera, sin el permiso escrito del editor y los autores.

\section{Publicación 8366-S}

\section{ISBN-13: 978-1-60107-639-7}

La Universidad de California prohíbe la discriminación o el hostigamiento de cualquier persona por razones de raza, color, origen nacional, religión, sexo, identidad en función del género, embarazo (inclusive parto y condiciones médicas relacionadas con el embarazo o el parto), incapacidad física o mental, estado de salud (casos de cáncer o de características genéticas), ascendencia, estado civil, edad, preferencia sexual, ciudadanía o condición de veterano (veterano con incapacidad específica, veterano que se haya retirado del servicio recientemente, veterano de la era de Vietnam o cualquier veterano que haya estado en servicio activo en una guerra, campaña o expedición para la cual una insignia de campaña haya sido autorizada), en cualquiera de sus programas o actividades.
La política de la Universidad se propone concordar con las disposiciones de las leyes federales y estatales procedentes.

Las preguntas sobre la política antidiscriminatoria de la Universidad pueden dirigirse a: Affirmative Action/Staff Personnel Services Director, University of California, Agriculture and Natural Resources, 1111 Franklin St., 6th Floor, Oakland, CA 94607-5201, (510) 987-0096. Para obtener información acerca de cómo obtener esta publicación, llame al 1-800-994-8849.

Para simplificar la información, se han usado nombres comerciales de productos. No se intenta respaldar el producto mencionado o ilustrado, ni insinuar una crítica a productos similares que no se nombran o aparecen ilustrados.

Una versión electrónica de esta publicación está disponible en el sitio web de ANR Communication Services, http://anrcatalog.ucdavis.edu.

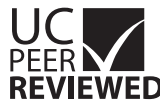

Esta publicación ha sido revisada anónimamente por científicos y especialistas de la Universidad de REVIEWED California y de otras instituciones para asegurar su contenido técnico. El proceso de revisión estuvo a cargo de los editores asociados para Horticultura Ambiental y para Publicaciones en Español de ANR.

web-10/09-LR/CR 


\section{Pregunte a un Jardinero}

Maestro de la UC

\section{Seguridad}

alimentaria en su

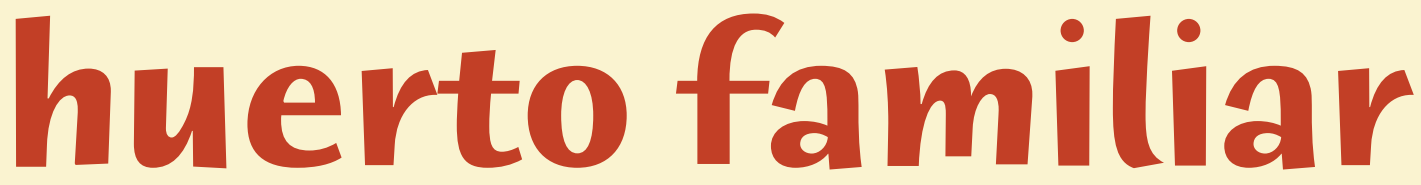

\section{Del huerto a la cocina, hay muchas} oportunidades para que bacterias, virus y parásitos contaminen las frutas y verduras.

\section{El agua, herramientas, animales y el} suelo contaminado por estiércol pueden propagar organismos dañinos en su huerto.

Para más información, contacte a los Jardineros Maestros locales (http://camastergardeners.ucdavis.edu).

Agradecemos el apoyo para este proyecto de Elvenia J. Slosson Research Endowment for Ornamental Horticulture. Contenido usado en esta publicación fue tomado, con permiso, de Food Safety Begins on the Farm - Reduce Microbial Contamination with Good Agricultural Practices, por Elizabeth A. Bihn, Robert B. Gravani, Janet E. Hawkes, Marvin P. Pritts, Anusuya Rangarajan y Donna L. Scott. Nuestras gracias a Trevor Suslow por la revisión y sugerencias técnicas.

Manejo del proyecto: Pamela M. Geisel; Donna C. Seaver. Traducción al español: Andrew Kramer y Myriam Grajales-Hall. Ilustraciones y diseño del póster: Will Suckow llustración. 


\section{Reduzca el riesgo de contaminar frutas y verduras cultivadas en su huerto}

\section{Suelo limpio}

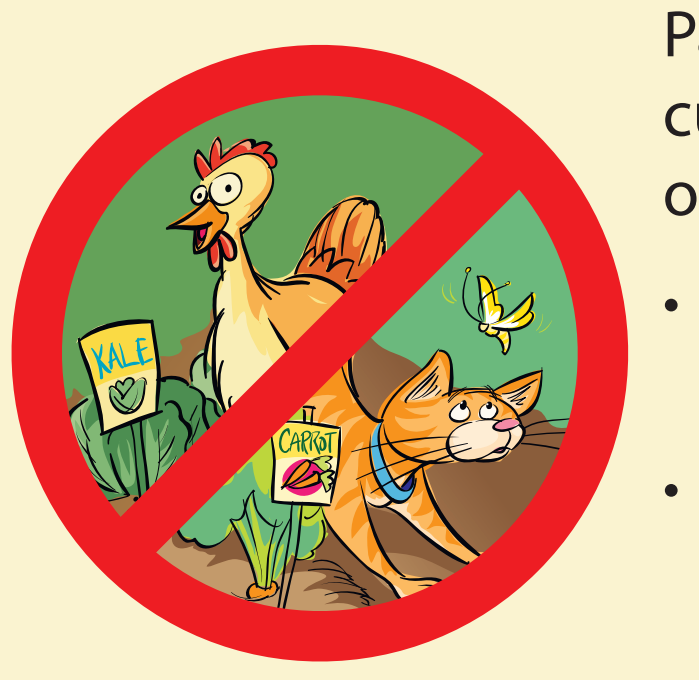

Para mayor seguridad, no utilice estiércol al cultivar verduras con hojas comestibles $u$ otros productos que se comen crudos.

No agregue estiércol fresco a los montones de abono (compost)

Mantenga a animales silvestres y domésticos fuera del huerto

\section{Agua limpia}

Esté al tanto de la calidad de su agua de riego.

- Utilice agua municipal de la llave o agua de un pozo construido correctamente y al cual se le hagan pruebas con regularidad en busca de la bacteria E. coli.

- Utilice riego por goteo para no mojar las superficies de hojas y frutas.

- Utilice agua de la llave al regar por encima o si riega por aspersión las partes comestibles de las plantas.

- Lave las frutas y verduras bajo el agua de la llave en vez de lavarlas en un tazón.

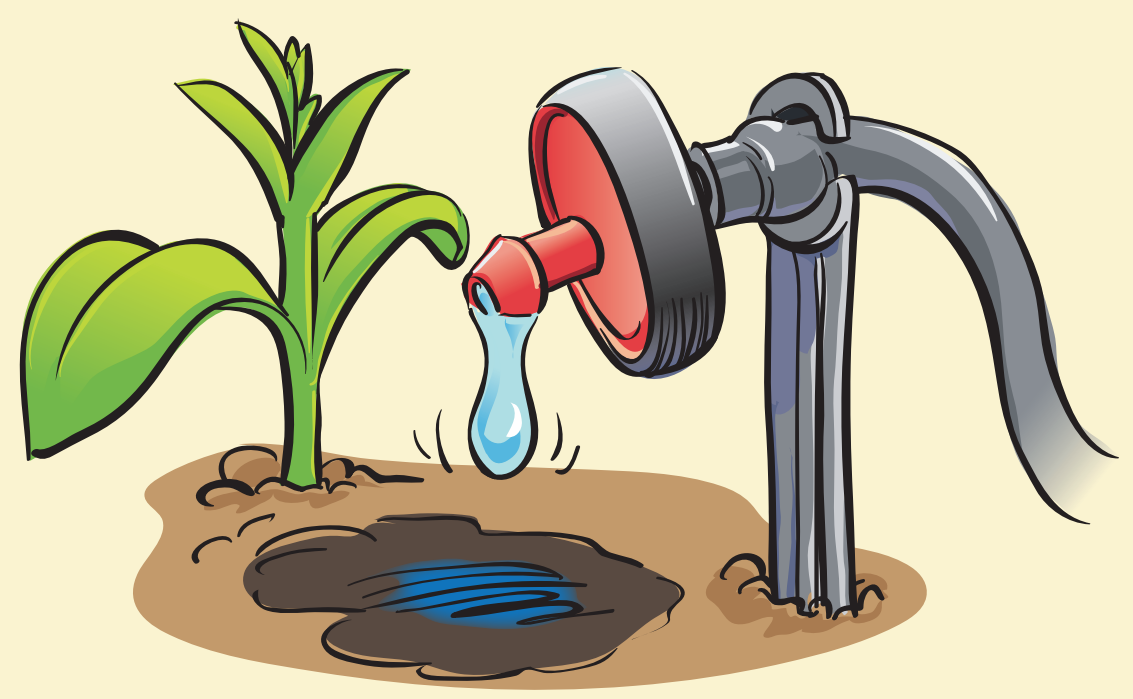




\section{Reduzca el riesgo de contaminar frutas y verduras cultivadas en su huerto}

\section{Manos limpias}

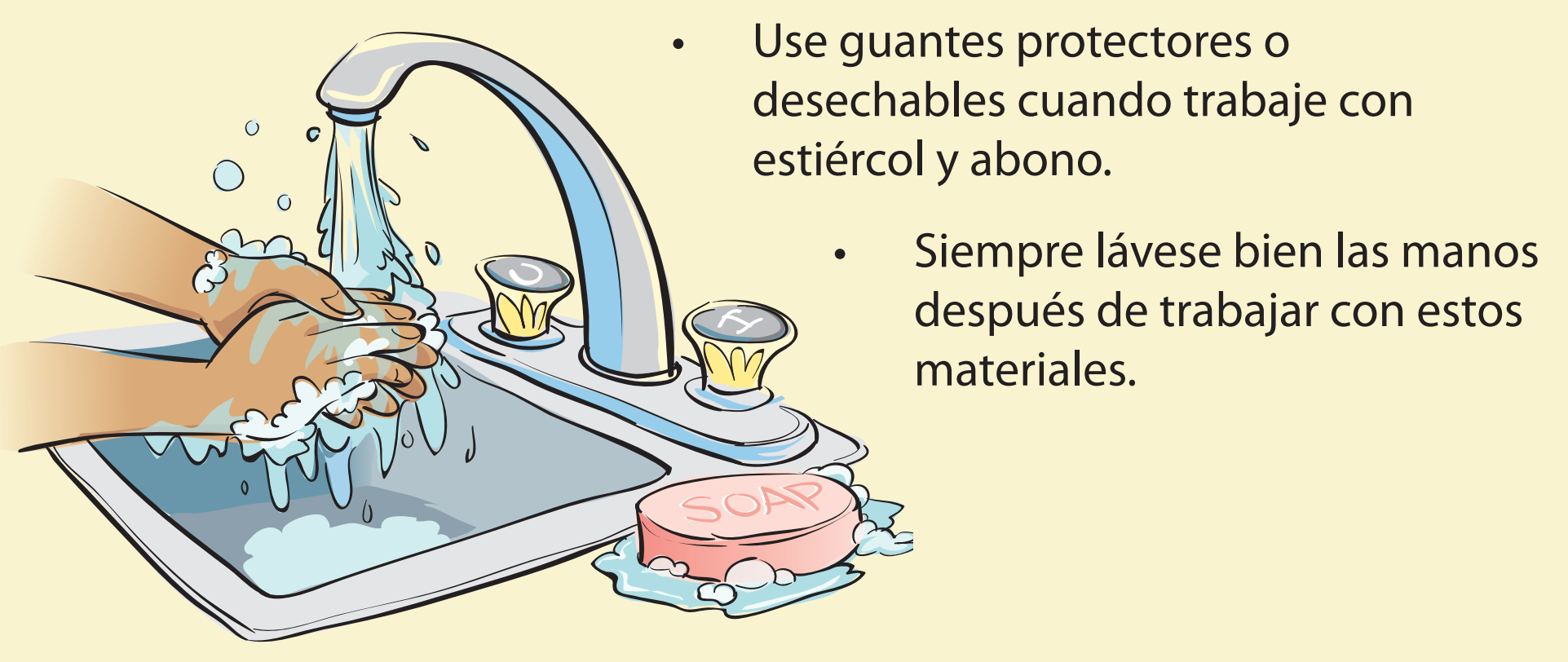

\section{Superficies limpias}

- Antes y durante la cosecha, utilice herramientas, guantes, contenedores y superficies de trabajo limpios.

- Lave con la manguera herramientas, zapatos o botas en un lugar alejado del huerto.

- Blanqueador diluido (1 cucharadita en 4 tazas de agua) o vinagre blanco puro son seguros para desinfectar las superficies de trabajo.

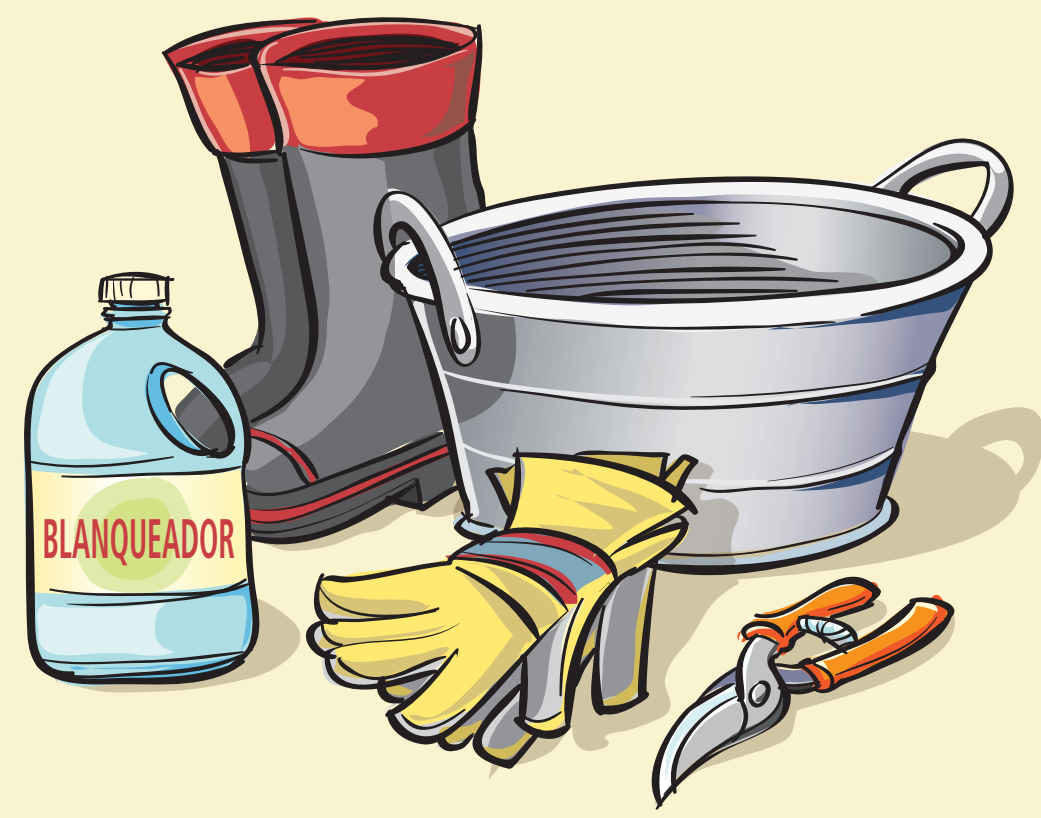


Contents

Reduzca el riesgo de contaminar los alimentos que cultiva en su huerto

Suelo limpio

Agua limpia

Manos limpias

Superficies limpias

Considere la seguridad alimentaria en cada fase de su huerto familiar ANTES DE SEMBRAR

Producción

Cosecha

Manejo de poscosecha

RECURSOS EN LÍNEA

Sitios web

En español

En inglés

Publicaciones /Folletos

En español

En inglés

REFERENCIAS

CONVERSIONES INGLÉS-MÉTRICO

INFORMACIÓN DE PEDIDOS 